\title{
PENGARUH IKLIM KERJA TERHADAP KELELAHAN TENAGA KERJA
}

\author{
Lintang Eka, Darjati*, Agnes Theresia DN
}

Jurusan Kesehatan Lingkungan, Poltekkes Kemenkes Surabaya

*Email korespondensi: darjati surabaya@yahoo.com

\begin{abstract}
ABSTRAK
Lingkungan kerja merupakan segala sesuatu yang berada di sekitar tenaga kerja yang dapat mempengaruhi pekerja dalam melaksanakan pekerjaanya. Dalam lingkungan kerja yang panas, tenaga kerja mendapatkan beban tambahan berupa tekanan panas yang dapat menyebabkan kelelahan. Penelitian ini dilakukan untuk melihat pengaruh iklim kerja terhadap kelelahan tenaga kerja bagian bengkel konstruksi di PT Dok dan Perkapalan Surabaya Tahun 2019.

Jenis Penelitian ini bersifat analitik dengan menggunakan pendekatan cross sectional. Sampel dalam penelitian ini adalah seluruh tenaga kerja bagian bengkel konstruksi yang berjumlah 20 orang. Pengumpulan data melalui kegiatan observasi dan wawancara. Pengukuran iklim kerja menggunakan alat Pshichrometer, thermometer, globe thermometer, dan anemometer. Sedangkan pengukuran kelelahan tenaga kerja menggunakan kuisioner alat ukur perasaan kelelahan kerja dan uji asam laktat. Analisis data menggunakan uji Chi Square. Dimana kriteria pengujian Ho diterima jika $p>0,05$ dan Ho ditolak jika $\mathrm{p}<0,05$.

Hasil penelitian ini menunjukkan bahwa suhu iklim kerja panas tertinggi mencapai $30,8{ }^{\circ} \mathrm{C}$, dengan tingkat kelelahan tinggi yang banyak dirasakan sebesar 93,3\%. Dari hasil uji statistic menunjukkan bahwa ada pengaruh iklim kerja terhadap kelelahan tenaga kerja di bengkel konstruksi PT. Dok dan Perkapalan Surabaya berdasarkan titik pengukuran menunjukkan hasil yang signifikan yaitu $0,0013(p<0,05)$.

Kesimpulan dari penelitian ini adalah ada pengaruh iklim kerja terhadap kelelahan tenaga kerja pada bagian konstruksi di PT. Dok Dan Perkapalan Surabaya. Disarankan agar pihak perusahaan menambahkan pendingin ruangan untuk menurunkan suhu panas. Para tenaga kerja juga harus istirahat yang cukup dan banyak minum air.
\end{abstract}

Kata Kunci : Iklim Kerja, Kelelahan Tenaga Kerja

\section{PENDAHULUAN}

Dewasa ini sektor industri berkembang secara pesat sehingga banyak industry berlomba-lomba memperluas usaha dan jaringan kerjasamanya. Untuk mendukung kegiatan industrinya, sebuah perusahaan malakukan pembangunan instalasi dan usaha-usaha untuk menambah hasil produksi. Seringkali dalam kegiatan tersebut pihak industry hanya mengutamakan keuntungan dan kurang peduli terhadap kerusakan lingkungan yang ditimbulkan (Cahyono, 2009).

Undang-Undang Nomor 36 Tahun

2009 tentang Kesehatan mengatur hak dan kewajiban setiap warga Negara dalam memelihara dan meningkatkan derajat kesehatan. Dalam Undang Undang tersebut juga dinyatakan bahwa upaya kesehatan kerja merupakan salah satu dari upaya kesehatan yang diselenggarakan untuk mewujudkan produktivitas kerja yang optimal selaras dengan perlidungan tenaga kerja.

Menurut Peraturan Menteri Tenaga Kerja dan Transmigrasi Per. 13/MEN/X/2011, Iklim kerja merupakan hasil perpaduan antara suhu, kelembaban, kecepatan gerak udara dan panas radiasi akibat dari tingkat pengeluaran panas tubuh tenaga kerja sebagai akibat dari pekerjaanya.

Di Indonesia mengenai kegiatan kerja di industri yang dapat menimbulkan iklim kerja, diatur dalam Peraturan Mentri Tenaga Kerja dan Transmigrasi No.PER. $13 / \mathrm{MEN} / \mathrm{X} / 2011$ yaitu $31,0^{\circ} \mathrm{C}$ untuk beban kerja ringan, $28,0^{\circ} \mathrm{C}$ untuk beban kerja sedang, dan $25,9^{\circ} \mathrm{C}$ untuk beban kerja berat dalam waktu kerja 8 jam sehari dengan istirahat 1 jam.

Iklim kerja yang panas dapat mempengaruhi salah satu fungsi tubuh 
manusia, seperti tenakan darah, kecepatan denyut nadi dan jantung, ketahanan fisik, dan daya konsentrasi. Suhu lingkungan kerja yang meningkat maupun menurun dapat mempengaruhi penurunan maupun peningkatan tekanan darah pekerja (Suma'mur, 2009).

Lingkungan kerja merupakan segala sesuatu yang berada di sekitar para pekerja yang berperan penting serta dapat mempengaruhi diri pekerja tersebut dalam menjalankan tugas yang di berikan. Dalam lingkungan kerja yang panas, tenaga kerja mendapatkan beban kerja tambahan berupa tekanan panas dan menyebabkan kelelahan(Suma'mur, 2009).

Kelelahan merupakan suatu perasaan yang bersifat subjektif. Kelelahan adalah keadaan yang disertai dengan penurunan fisiensi dalam bekerja. dan kelelahan merupakan bentuk dari mekanisme perlindungan agar tubuh terhindar dari kerusakan lebih parah, sehingga akan terjadi pemulihan (Suma'mur, 2009).

Tujuan dari penelitian ini yaitu untuk mengetahui pengaruh iklim kerja terhadap kelelahan tenaga kerja bagian bengkel konstruksi di PT Dok dan Perkapalan Surabaya

\section{METODE PENELITIAN}

Peneliian ini merupakan penelitian analitik yang menggunakan analisis data untuk membuktikan hubungan antara variabel. Penelitian ini menggunakan pendekatan cross sectional dimana penelitian ini dilakukan pada satu waktu tertent. Jumlah sampel dalam penelitian ini sebanyak 30 responden.

Variabel bebas dalam penelitisn ini adalah iklim kerja pada bagian bengkel konstruksi, Variabel terikat adalah kelelahan pada tenaga kerja pada bagian produksi di PT Dok dan Perkapalan Surabaya, dan variabel penganggu adalah umur, lama kerja, kebisingan, dan pencahayaan.

Teknik pengumpulan data pada penelitian ini adalah observasi, wawancara, dan pengukuran. Analisis data dalam penelitian ini menggunakan uji chi square untuk mengetahui ada tidaknya pengaruh antara variabel.

\section{HASIL DAN PEMBAHASAN Iklim Kerja}

Tabel 1

DISTRIBUSI FREKUENSI IKLIM KERJA TERHADAP TENAGA KERJA

\begin{tabular}{llcc}
\hline No & Iklim Kerja & $\mathrm{N}$ & $(\%)$ \\
\hline 1. & Memenuhi & 5 & 16,7 \\
& Syarat \\
2. & Tidak & 25 & 83,3 \\
& $\begin{array}{l}\text { Memenuhi } \\
\text { Syarat } \\
\text { Total }\end{array}$ & & \\
& 30 & 100 \\
\hline \multicolumn{3}{c}{ Berdasarkan hasil } & pengukuran
\end{tabular}
menggunakan alat thermometer globe pada 5 titik yaitu marking, cutting, bending, sub assembling, dan assembling. Didapat hasil bahwa iklim kerja yang memenuhi syarat dan normal sebesar $16,7 \%$ dan iklim kerja yang tidak memenuhi syarat dan melebihi NAB sebanyak $83,3 \%$. Iklim kerja yang tidak sesuai dapat menimbulkan gangguan kesehatan dan mengakibatkan kelelahan kerja (Suma'mur, 2009).

Hasil wawancara dengan tenaga kerja, iklim kerja di bagian konstruksi di PT. Dok dan Perkapalan Surabaya yang melebihi NAB mengakibatkan tenaga kerja mudah berkeringat dan cepat haus. Hal ini sesuai dengan teori Suma'mur (2009) bahwa iklim kerja yang panas dapat merangsang tubuh untuk berkeringat dalam jumlah banyak, sehingga tubuh akan kehilangan banyak cairan. Jika kondisi tersebut terjadi dalam jangka waktu yang lama maka dapat mengakibatkan kelelahan.

Menurut Peraturan Menteri Tenaga Kerja dan Transmigrasi Per. 13/MEN/X/2011, Iklim kerja merupakan hasil perpaduan antara suhu, kelembapan, kecepatan gerak udara dan panas radiasi akibat dari tingkat pengeluaran panas dari tubuh tenaga kerja sebagai akibat dari pekerjaanya. Iklim kerja yang tinggi dapat menyebabkan suhu tubuh meningkat sehingga tubuh berkeringat dan menyebabkan kelelahan.

Upaya pengendalian iklim kerja dapat dilakukan dengan cara pemasangan exhauster. Exhauster berguna untuk menghisap udara panas dalam ruangan dan membuangnya ke luar, dan saat bersamaan menghisap 
udara segar dari luar ruangan untuk masuk ke dalam ruangan.

\section{Kelelahan Tenaga kerja}

Tabel 2

DISTRIBUSI FREKUENSI KELELAHAN PADA TENAGA KERJA BAGIAN BENGKEL KONSTRUKSI

\begin{tabular}{llcc}
\hline No & Kelelahan & Fr & $\mathbf{( \% )}$ \\
\hline 1. & Kelelahan & 2 & 6,7 \\
& Normal & & \\
2. & $\begin{array}{l}\text { Kelelahan } \\
\text { Tinggi } \\
\text { Total }\end{array}$ & $\mathbf{3 0}$ & $\mathbf{1 0 0}$
\end{tabular}

Berdasarkan hasil penelitian menggunakan uji asam laktat dalam darah pada tenaga kerja di bengkel konstruksi PT. Dok dan Perkapalan Surabaya, dapat disimpulkan bahwa dari 28 tenaga kerja mengalami kelelahan kerja tinggi dan sisanya 2 tenaga kerja mengalami kelelahan normal. Sedangakan berdasarkan hasil penelitian menggunakan kuisioner alat ukur perasaan kelelahan kerja (KAUPK2), Kelelahan yang dialami tenaga kerja di bengkel konstruksi sebagian besar para tenaga kerja tidak merasa lelah sebesar $83,3 \%$ dan tenaga kerja yang mengalami kelelahan sebesar $16,7 \%$ dari total 30 tenaga kerja

Pada saat penelitian para tenaga kerja juga mengeluhkan gangguan kesehatan antara lain sering berkeringat, mudah haus, cenderung lupa dan ketidaknyamanan pada punggung dan bahu saat bekerja. Hal tersebut merupakan tanda-tanda tenaga kerja mengalami kelelahan kerja.

Kelelahan harus di perhatikan oleh perusahaan dikarenakan dapat berdampak kepada penyakit akibat kerja (PAK) dan dapat menurunkan produktivitas kerja.
Kelelahan tenaga kerja dapat ditimbulkan oleh faktor individu dan faktor lingkungan. Penyebab kelelahan pada tenaga kerja di bengkel konstruksi berasal dari faktor lingkungan fisik berupa iklim kerja, kebisingan dan pencahayaan. Serta lingkungan individu seperti umur dan lama kerja juga dapat mempengaruhi kelelahan kerja.

Dampak buruk dari kelelahan bagi tenaga kerja antara lain penurunan kualitas kerja, terjadinya banyak kesalahan kerja, motivasi untuk bekerja menurun, cedera, penyebab akibat kerja, kecelakaan kerja, stress kerja dll. Tetapi dampak buruk yang ditimbulkan dapat dicegah. Oleh karena itu untuk menghindari dampak buruk yang ditimbulkan oleh kelelahan kerja dibutuhkan kesadaran dan kerja sama oleh para tenaga kerja dan juga perusahaan untuk memberikan informasi tentang pengertian kelelahan kerja, penyebab kelelahan kerja, gejala kelelahan kerja, dampak kelelahan kerja, dan cara pemulihan kelelahan kerja. Selain itu para tenaga kerja harus memanfaatkan waktu istirahat yang diberikan oleh perusahaan dengan baik dan seoptimal mungkin.

Untuk mengurangi kelelahan yang dialami oleh para tenaga kerja di bengkel konstruksi maka dapat dilakukan dengan membiasakan para tenaga kerja untuk melalakukan peregangan otot seperti menggerakkan kepala, tangan, dan kaki disela-sela pekerjaan dan di waktu istirahat. Peregangan otot yang teratur dapat bertujuan untuk melancarkan sirkulasi darah ke seluruh tubuh sehingga tubuh tidak terlalu lama dalam keadaan statis yang dapat mengakibatka para tenaga kerja menjadi cepat lelah dan tidak gesit dalam bekerja.

Tabel 3

DISTRIBUSI IKLIM KERJA TERHADAP KELELAHAN PADA TENAGA KERJA

\begin{tabular}{|c|c|c|c|c|c|c|c|}
\hline \multirow{3}{*}{ Iklim Kerja } & \multicolumn{4}{|c|}{ Kelelahan } & \multirow{2}{*}{\multicolumn{2}{|c|}{ Total }} & \multirow{3}{*}{$\frac{P}{0,013}$} \\
\hline & \multicolumn{2}{|c|}{$<2,2 \mathrm{Mmol}$} & \multicolumn{2}{|c|}{$>2,2 \mathrm{Mmol}$} & & & \\
\hline & $n$ & $\%$ & $\mathrm{n}$ & $\%$ & $\mathrm{n}$ & $\%$ & \\
\hline Memenuhi Syarat & 0 & $0,0 \%$ & 5 & $100 \%$ & 5 & $100 \%$ & \\
\hline Memenuhi & 2 & $8,0 \%$ & 23 & $92,0 \%$ & 25 & $100 \%$ & \\
\hline Total & 2 & $6,7 \%$ & 8 & $93,3 \%$ & 30 & $100 \%$ & \\
\hline
\end{tabular}


Berdasarkan hasil pengukuran menggunakan alat thermometer globe pada 5 titik yaitu marking, cutting, bending, sub assembling, dan assembling. Pengukuran ini bertujuan untuk menggambarkan keadaan lingkungan pada saat tenaga kerja melakukan pekerjaannya yang cukup tinggi. Diperoleh nilai ISBB untuk titik yang pertama sebesar $28,8{ }^{\circ} \mathrm{C}$, titik kedua dengan ISBB $30,8^{\circ} \mathrm{C}$, titik ketiga dengan $30^{\circ} \mathrm{C}$, titik keempat dengan $30,5^{\circ} \mathrm{C}$, dan titik kelima sebesar $30,7^{\circ} \mathrm{C}$. Menurut Peraturan Menteri Ketenagakerjaan Nomor 5 Tahun 2018 Tentang Nilai ambang batas (NAB) Iklim kerja dengan parameter indeks suhu basah dan bola (ISBB) sebesar $29^{\circ} \mathrm{C}$.

Dari hasil penelitian yang telah dilakukan diperoleh tenaga kerja yang terpapar iklim kerja yang tidak memenuhi syarat dan paling banyak mengalami kelelahan tinggi sebanyak $92,9 \%$ dan tenaga kerja yang terpapar iklim kerja memenuhi syarat dengan kelelahan normal sebanyak $8,0 \%$. Dari hasil uji statistic menggunakan chi square didapatkan nilai significancy 0,0013 . Karena $p$ value sebesar $0.0013<a=$ 0,05 maka Ho di tolak yang artinya ada pengaruh iklim kerja terhadap kelelahan tenaga kerja di bengkel konstruksi PT. Dok dan Perkapalan Surabaya tahun 2019.

Hasil penelitian ini sejalan dengan penelitian Kristanti (2011) tentang hubungan antara tekanan panas dengan kelelahan kerja pada tenaga kerja bagaian produksi di CV. Rakabu Surakarta dengan hasil analisis bahwa nilai $p<0,05$ yang artinya ada hubungan antara tekanan panas dengan kelelahan kerja.

Tenaga kerja yang terpapar oleh iklim kerja akan menyebabkan suhu tubuh meningkat. Tenaga kerja dalam melakukan pekerjaannya akan menghasilkan panas tubuh (metabolik) dan keringat. Ketika suhu lingkungan tinggi maka dapat mengganggu proses perpindahan panas dari dalam keluar tubuh. Suhu panas dapat mengurangi kelincahan dalam bergerak, memperpanjang waktu reaksi, dan memperlampat waktu pengambilan keputusan serta mengakibatkan ketidaknyamanan pada tenaga kerja saat melakukan pekerjaannya (Suma'mur, 2009).

Upaya pengendalian iklim kerja dapat dilakukan dengan cara pemasangan exhauster tambahan untuk mengurangi rasa gerah karena kondisi lingkungan yang panas.

\section{KESIMPULAN}

Berdasarkan hasil penelitian yang telah dilakukan, maka dapat disimpulkan bahwa ada pengaruh iklim kerja terhadap kelelahan tenaga kerja di bengkel konstruksi PT. Dok dan Perkapalan Surabaya tahun 2019.

\section{SARAN}

Berdasarkan kesimpulan penelitian, maka penelitian merekomendasikan bagi perusahaan untuk memberikan pengetahuan tentang pengertian, penyebab, gejala, dampak dan cara memulihkan kelelahan. Tenaga kerja harus mematuhi semua peraturan yang sudah diterapkan oleh perusahaan seperti menggunakan sepatu safety, helm, ear plug, dll., membiasakan diri untuk melakukan peregangan otot.

\section{DAFTAR PUSTAKA}

Balai Hiperkes, (2011). Praktikum Laboratorium Hiperkes bagi mahasiswa. Yogyakarta : Dinas Tenaga Kerja dan Transmigrasi.

Budiman. (2011). Penelitian Kesahatan. Bandung: PT Refika Adhitama

Departemen Tenaga Kerja dan Transmigrasi Republik Indonesia. (2011). PER.13/MEN/X/2011 Tentang Nilai Ambang Batas Faktor Fisika Dan Faktor Kimia Di Tempat Kerja. Depnakertrans RI. Jakarta Indonesia.

Elyastuti, F. (2010). Hubungan Antara Iklim Kerja dengan Tingkat Kelelahan Tenaga Kerja Bagian Fabrikasi di Pabrik Gula Trangkil, Pati. [Skripsi]. Jawa Tengah.Peraturan Menteri Ketenagakerjaan Nomor 5 Tahun 2018 Tentang K3 Lingkungan Kerja 
Riyanti, A. (2010). Pengolahan dan Analisis Data Kesehatan. Yogyakarta: Nuha Medika.

Setiawan, D dan Prasetyo H., (2015). Metodologi Penelitian Kesehatan untuk Mahasiswa Kesehatan. Yogyakarta : Graha IImu.

Setyawati, L. M. (2010). Selintas Tentang Kelelahan Kerja. Yogyakarta: Amara Books.

Siswatiningsih. (2010). Perbedaan Denyut Nadi Sebelum Dan Sesudah Bekerja Pada Iklim Kerja Panas Unit Workshop PT. Indo Acidatama Tbk Kemiri,Kebakkramat, Karanganyar. [Skripsi]. Surakarta: Program DIII Hiperkes\& Keselamatan Kerja Fakultas Kedokteran UNS.

SNI 16-7061-2004 Tentang Pengukuran Iklim Kerja (Panas) dengan Parameter Indeks Suhu Basah dan Bola

SNI 16-7062-2004 Tentang Pengukuran Intensitas Penerangan di Tempat Kerja
Suma'mur, P K., 2009. Higiene Perusahaan dan Keselamatan Kerja (HIPERKES). Jakarta : CV. Sanggung Seto.

Subaris H dan Haryono. (2008). Higiene Lingkungan Kerja. Yogjakarta : Mitra Cendikia Press.

Swarjana, I Ketut., 2012. Metodologi Penelitian Kesehatan. Yogyakarta : Andi .

Tarwaka, 2011 . Ergonomi Industri. Surakarta : HARAPAN PRESS.

Undang-Undang Republik Indonesia Nomer 32 Tahun 2009 tentang Perlindungan dan Pengolahan Lingkungan Hidup.

Wardhana, Wisnu Arya., (2011). Dampak Pencemaran Lingkungan. Yogyakarta, Andi Yogyakarta.

Wibowo, AE. (2012). Aplikasi Praktis SPSS Dalam Penelitian. Yogyakarta: Gava Media. 